\title{
ASSESSING CROPLAND ABANDONMENT FROM VIOLENT CONFLICT IN CENTRAL MALI WITH SENTINEL-2 AND GOOGLE EARTH ENGINE
}

\author{
Laure Boudinaud ${ }^{1}$, Sacha Alex Orenstein ${ }^{2}$ \\ 1 World Food Programme, Regional Bureau of West and Central Africa; Dakar, Senegal; laure.boudinaud@wfp.org \\ 2 DaCarte; Dakar, Senegal; alex@dacarte.com
}

KEY WORDS: Remote Sensing, Armed Conflict, Land Cover / Land Use, Agriculture, Cloud Computing, Open Geospatial.

\begin{abstract}
:
The proposed analysis based on Sentinel-2 imagery provides evidence of impacts of the conflict in the Mopti region (central Mali), which has led to widescale cropland abandonment. This area is characterized by rapidly rising levels of violence since 2018, due to the presence of armed groups and the proliferation of self-defence militias. This study investigates how high-resolution optical imagery can help evaluate the linkages between violence and land cover / land use (LCLU) change. The processing environment of Google Earth Engine was used to generate the so-called 3-Period TimeScan (3PTS) product, a RGB composite combining the maximum NDVI values in the beginning, in the middle and in the end of the growing season, used to single out cultivated land for each year of interest. Theoretically, the period between June $15^{\text {th }}$ and October $15^{\text {th }}$ covers an annual agricultural cycle for the considered area; consequently, images acquired during that period were used to generate the 3PTS composites for the year of interest (2019) and for pre-conflict years. By comparing the situations before and after the start of the crisis, each populated site was categorized according to the degree of cropland change detected in its surroundings. The resulting overview map enables a regionalscale interpretation of farming activities in 2019, clearly highlighting localized areas of cropland abandonment in the region and showing a strong spatial correlation with incidence of conflict.
\end{abstract}

\section{INTRODUCTION}

Tensions around the use of land for grazing and agriculture have existed for long between communities in central Mali, but it has recently become intertwined with wider political and interethnic clashes (Benjaminsen, 2018), leading to a rapid escalation of violence. This has fostered an emergency crisis, requiring humanitarian actors to plan their response quickly and efficiently. Cropland mapping is essential to inform such decisions, as it may indicate not only physical security, or lack thereof, but also food security. Typically, in the absence of extensive field data, publicly available LCLU datasets are used to identify cropland cover. However, while such datasets have proliferated over the years, they are often ill-adjusted to the Sahelian context and insufficiently accurate to draw a reliable picture of cropland in Mali. Given the important physical access restrictions due to the security context, the ability to remotely assess cultivated areas in central Mali is of critical importance.

\subsection{Context of Mali}

Mali is a vast land-locked country in the heart of the Sahel. This region is characterized by a unique agroecological system as it forms a transitional zone between the arid Sahara to the north and the belt of humid savannas to the south. Social indicators of Mali remain amongst the lowest in the world, and the country ranks 184 out of 189 on UNDP's 2018 Human Development Index. Demographic growth is amongst the highest in the world: projections suggest that the population of Mali, approximately 20 million in 2020, will double in the next 25 years (UNDESA, 2019). In addition to mounting demographic pressures, the country's economy has been marked for decades by extreme poverty, insufficient basic social services and youth unemployment, a situation exacerbated by repeated droughts (Gingembre, 2019). Such pressures destabilize livelihoods, which are dominated by agriculture and livestock (ILOSTAT) and represent a challenge for communities who compete for scarce land and water resources. Since a political coup in March 2012, most of northern Mali has been occupied by non-state armed groups. Local conflicts have multiplied from the north to the centre of the country, hampering humanitarian access, and leaving large numbers of people highly vulnerable. A United Nations peacekeeping mission was deployed to the country in July 2013. Insecurity data registered thousands of civilian fatalities in 2019 throughout Mali (ACLED, 2019). In addition, the number of internally displaced persons (IDPs) in the country increased from about 50,000 in March 2018 to almost 240,000 people two years later (IOM, 2020); in October 2020, 131,150 people were displaced in Mopti only. In the same period, an estimated 171,900 people were estimated to be food insecure, more than any other region in Mali (Cadre Harmonisé, 2020). Among humanitarian actors, agricultural production remains the backbone of food security needs assessments and is often the deciding factor in the declaration of a food crisis (CILSS, 2014). As such, changes in cropland area are a critical indicator of food insecurity, more specifically in rural areas that are disconnected from larger food markets and production systems.

\subsection{Gaps in agricultural data}

Accurate georeferenced data on cropland cover is not available for northern and central Mali. The most widely used reference source for estimating cultivated surface, FAOSTAT, mostly relies on data produced by national governments (FAO, 2020). While this data provides a quantitative estimation in hectares by administrative division, it is not spatial in nature and cannot be used to precisely localize cropland. Likewise, the accuracy of the data is in question, given that the most recent official agricultural census data in Mali dates from 2005 (RGA, 2007). Besides, state presence is typically weak in northern and central Mali, as evidenced by a lack of essential public services in areas outside of major towns (Centre for Humanitarian Dialogue, 2020). Furthermore, as collecting field data in an ongoing conflict zone presents enormous hazards, it is difficult to generate accurate land use data in this area. This lack of georeferenced field data has created a dependency on remotely sensed imagery for assessing cropland cover in northern and central Mali. While Very High Resolution (VHR) imagery 
could be used to identify active cropland, the cost to acquire recent imagery over such a wide area and the time associated with its analysis is prohibitive for creating regular and timely data. As a result, it is unlikely that updated cadastral data would be made available for that area. Publicly available LCLU datasets such as FAO-GLC (Latham, 2014), GlobCover (Arina, 2008) or CCI Land Cover (Defourny, 2016) are often used by both researchers and practitioners alike. The cropland information provided by those LCLU products, available at a global or continental scale, varies substantially among the different datasets and has a poor accuracy in Sahelian countries, especially in the Sahelian band (Pérez-Hoyos, 2017). An assessment conducted by Samasse (2018) looking at eight different landcover datasets found none that reach a $75 \%$ accuracy threshold over Mali, Niger, Burkina Faso, Niger, Mauritania, or Senegal for cropland, with an average overestimation of cultivated areas of $170 \%$. Intense seasonal changes in land cover and important cropland fragmentation help to explain the poor accuracy of LCLU datasets in the Sahel (Wei, 2020; Nabil, 2020). Indeed, agriculture in those areas remains mostly unmechanized: in Mali, $98 \%$ of crop fields have a size below 1.5 hectares (GEOGLAM, 2015). Given the relatively low spatial resolution of typical LCLU datasets (ranging from $300 \mathrm{~m}$ to $1 \mathrm{~km}$ ), their use is insufficient for fine scale agricultural monitoring. Experimentations of higher resolution datasets include Globeland30 (Gong, 2013), which provides global land coverage based on the exploitation of the Landsat archive at 30 meters, but is available for 2010 only, and Sen2Agri (Defourny, 2019), for which Mali was the first national demonstration site in 2016. However, Sen2Agri products, which rely on extensive field data and Sentinel-2 data, focus on the cotton-belt region (southern part of the country), excluding northern Sahelian zones (Lamarche, 2018). Thus, no reliable, up-to-date, and regional-scale cropland data was available for the area of interest when the crisis started in central Mali, a time when such data is critically needed to assess vulnerability hotspots and respond to a growing humanitarian crisis. The method outlined in this paper aims to provide an accessible solution to address such information gaps.

\section{METHODOLOGY}

The proposed method consists of a highly localized cropland change analysis between two years (before and after the start of the conflict). For that, so-called 3-Period TimeScan (3PTS) products are generated for each year. Inspired by the TimeScan developed by Esch (2018), it consists of a Red-Green-Blue composite where the red band represents the maximum NDVI value during the first period of the growing season, the green the maximum NDVI in the middle, and the blue the maximum NDVI at the end. This technique enables to condense the information on the temporal evolution of the agricultural season, and in doing so, to single out cropland from other landcover types. Input to the processing chain are top-ofatmosphere Sentinel-2 image tiles, available in Google Earth Engine (GEE), a cloud-based platform providing massive computational capabilities and access to a large catalogue of remote sensing datasets (Gorelick, 2017). The results presented in this paper are derived from the comparison of the 2019 3PTS product with the one of 2017, which is a year prior to the start of the security degradation in the region. The change status was visually determined per populated site, as supervised classifications required exhaustive manual cleaning to produce a reliable product over such a large and ecologically heterogenous zone. The results were compared to georeferenced data of violent events during the period of interest.

\subsection{Data}

The Sentinel-2 mission is particularly well-suited for cropland monitoring (ESA, 2017; Inglada, 2015). Its global coverage, high revisit time (5 to 6 days) and spatial resolution of 10 metres enable to depict agricultural fields over the entirety of the Mopti region, as it manages to detect small, non-mechanized agricultural fields, which are predominant in that area. Level-1C (L1C, top-of-atmosphere reflectance) was chosen over Level2A (L2A, surface reflectance) because of its systematic generation and online distribution (ESA, 2017). Indeed, while $721 \mathrm{~L} 1 \mathrm{C}$ elements are available in GEE for the period between $15^{\text {th }}$ June and $15^{\text {th }}$ October 2019 , over the area of interest, the equivalent L2A set contains only 697 elements. For the same period in 2017 and in 2016, there are respectively 640 and 678 L1C elements but no L2A product available. Consequently, a total of 2,039 Sentinel-2 L1C tiles were processed for this study. Tracking cultivation necessitates an accurate dataset of human settlements for the region, given that cropland in Mopti is typically found within a short distance of a village or hamlet. This would also be used to represent the results under the form of a regional map showing cropland change categories assigned to each locality. A point feature dataset representing populated sites in the region of Mopti was created based on the official list of villages used by the Malian Institute of Statistics (INSTAT) for the national census in 2009, enhanced by a combination of ancillary data including OCHA's Common Operational Datasets and OpenStreetMap. This dataset was additionally improved through visual inspection of raster datasets such as the High Resolution Settlement Layer (Facebook Connectivity Lab, 2016), Google Earth imagery and Sentinel-2 imagery. The manual revision allowed the extensive georeferencing of 3,166 populated sites in the Mopti region, ensuring all populated sites in the study area are covered by the analysis. The Armed Conflict Location and Event Data Project database was used to locate conflict events (ACLED). This openly-accessible database provides the location (latitude, longitude), dates and the number of fatalities associated with specific violent events registered through weekly updates. ACLED's sources include traditional media, reports from armed groups and civil society organizations as well as social media (Raleigh, 2010).

\subsection{Processing steps}

For each image of the collections, the Normalized Difference Vegetation Index (NDVI) was calculated. NDVI is a widely used remote sensing proxy for vegetation cover and has been successfully employed to monitor vegetation phenology and detect intra-annual changes, more specifically for cropland (Benedetti, 1993). It is calculated from the near-infrared and visible red reflectance values (Rouse, 1973). For the current study, spectral bands B4 and B8 of Sentinel-2 were used to calculate NDVI, leaving the spatial resolution of the 3PTS products at 10 metres. Positive values of NDVI refers to vegetation: higher values correspond to healthy and dense vegetation, while lower values show sparse vegetation. Water and built-up areas will be represented by near zero or negative values of NDVI. A single NDVI product provides an indication of vegetation presence on a given date, but it is not always sufficient to distinguish croplands from other types of vegetation (pasture, shrubs, etc.). A collection of single-date images covering the growing season must be considered to accurately depict the agricultural situation. Croplands are thus identified by their temporal evolution of NDVI values throughout the different phases of the agricultural season: photosynthetic activity of crops is low during the ploughingsowing period ("beginning" of the season, approximated by $15^{\text {th }}$ 
June to $1^{\text {st }}$ August in this study), increases during the growing phase ("middle", $2^{\text {nd }}$ August to $1^{\text {st }}$ September) until reaching a maximum value right before the harvest. Once harvested, NDVI values decrease drastically ("end of season", $2^{\text {nd }}$ September to $15^{\text {th }}$ October). Thus, the approach employed for investigating cropland change considers maximum NDVI values for three separate subperiods of the agricultural season and aggregates this information into a higher-level product, the 3PTS or 3Period TimeScan, reflecting the evolution in time of vegetation during the growing period. Pixel-based image compositing is a well-known technique (White, 2014) proposed as a solution to circumvent technical bottlenecks (e.g. the need for storage, high-performing processing infrastructure) and other restrictions related to satellite data availability, or the time required for exploiting results, which may otherwise hinder the usage of this data. The processing steps developed to produce cropland change maps are available under the form of a GEE script (Boudinaud, 2019), to which input parameters are the years of interest, the area of interest and the dates of the growing season for the considered area.

\subsection{Interpretation of 3PTS}

Because the 3PTS image condenses information per pixel on the temporal evolution of the vegetation over a full growing season, the different land cover types tend to be associated with specific colours, revealing LCLU patterns that are easy to interpret. Compared to natural vegetation, croplands are identified by higher and more abrupt changes of NDVI values over time throughout the different phases of the growing season. For that reason, croplands naturally single out on the 3PTS products. Figure 1 shows an example of a 3PTS composite over a village located in the AOI, in 2019. Built-up and human settlements, as well as water or rocks, are depicted in black (NDVI values are constantly low over time). Natural vegetation appears in grey tones, due to lower variations of natural vegetation over time, compared to cultivated areas, which appear as rectangles of different vivid colours, corresponding to different crop types, each with a specific vegetation curve over time.

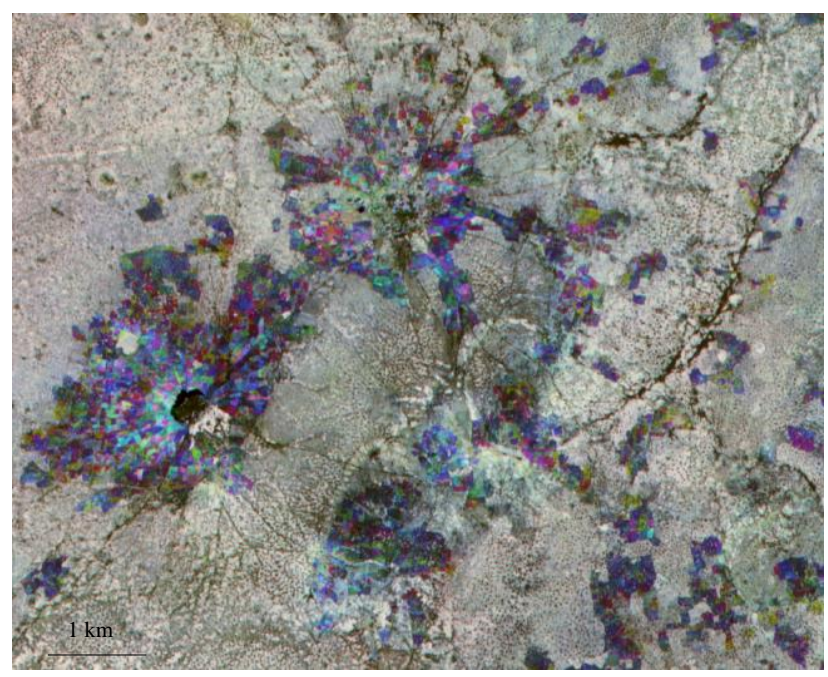

Figure 1. Example of a 3PTS composite for a village in 2019.

\subsection{Investigation of cropland changes}

The 3PTS technique was applied for each year of interest to support the identification of cropland changes before and after the start of the conflict. More specifically, they were determined comparing the 2019 3PTS product with the one of pre-conflict years: 2017 or, for confirmation or in the rare case of cloudy pixels, 2016. When visually comparing the two products, as shown in Figure 2 for the village of Bombou, it is possible to immediately detect the reduction in cropland areas that occurred in that zone between the two years.

The change status was determined per populated site, using the following classes:

- Severe decrease, where $>50 \%$ cropland loss is detected.

- Medium decrease, where cropland loss is $25 \%$ to $50 \%$.

- Slight decrease, where cropland loss is $<25 \%$.

- No change, where no change is detected.

- Slight increase, where cropland gain is $<25 \%$.

It shall be noted that no area showing a significant or medium increase in cropland was identified in the region in 2019.

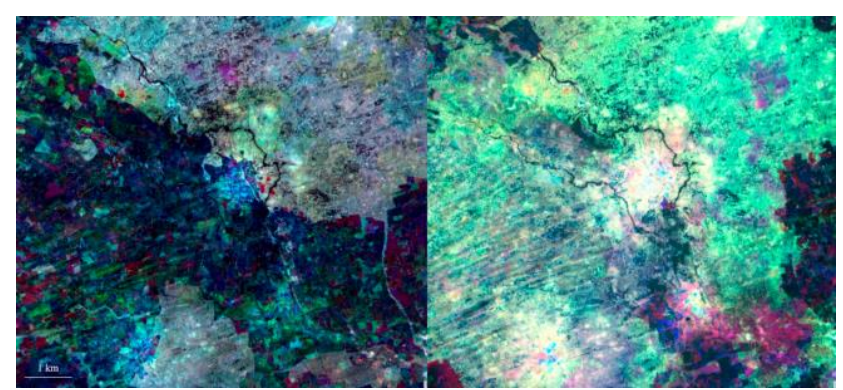

Figure 2. Severe cropland loss between 2017 (left) and 2019 (right) as detected on 3PTS products (village of Bombou).

\section{RESULTS}

This method enabled to identify 493 villages with significant cropland losses (medium or severe) in that year across Mopti region, and highlighted different types of impacts of the conflict on the landscape. More specifically, a recurring effect of concentration of cultivated fields in the proximity to habitations was observed, as well as settlement damage in a large number of localities. The map resulting in the cropland change analysis was compared with georeferenced data of conflict events, indicating a strong spatial correlation between violence and cropland reductions.

\subsection{Key points}

Following the steps presented in the previous sections, the resulting map was produced (Figure 3). In total in 2019, $25 \%$ of localities in the region of Mopti experienced a decrease in cultivated lands compared to pre-conflict years $(2017,2016)$. The cercles (level-2 administrative divisions of Mali) most affected by significant cropland losses are Koro, Bankass, Bandiagara and Douentza (eastern part of the region); these are the areas where intercommunal tensions have led to many acts of violence in the course of 2019. Besides, in more than 100 localities, noticeable changes in the distribution patterns of cropland fields could be detected in 2019 compared to preconflict years: while satellite imagery show that fields used to be cultivated as far as 10 kilometres away from settlements, the 2019 composite indicates that farmers only cultivated in direct proximity to habitations, within a radius ranging from 500 meters to 2 kilometres. On the other hand, no evident change was detected in most localities of the western cercles of the region: Youwarou, Mopti, Tenenkou and Djenne experienced fewer cropland losses than eastern Mopti. Finally, for a minority 
of localities (2.9\%), croplands slightly increased in 2019 compared to pre-conflict years. This may be due to favourable climatic conditions, despite a late start of the rainy season, or a consequence of population displacement in safer localities within the region.

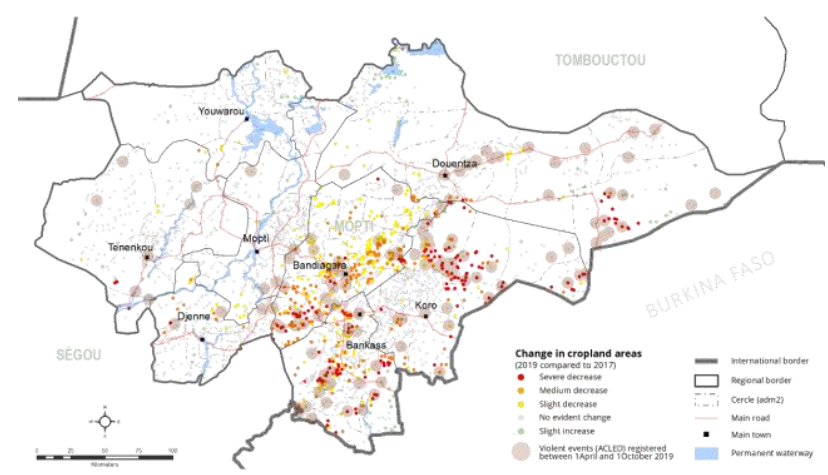

Figure 3. Cropland change and violent events in 2019 in Mopti.

\subsection{Cropland abandonment and incidence of conflict}

The overlapping of violent events registered between April and October 2019 with the results of the cropland change analysis illustrates a clear correlation between insecurity and agricultural decline. In June 2019, when land preparation and planting were underway, a peak in both the numbers of violent events and fatalities was recorded in the region of Mopti (ACLED, 2019). Most of the significant cropland losses occurred in localities where violent events were registered between April and October 2019. During that period, 190 of the 305 violent events reported for Mali occurred in the Mopti region, $90 \%$ of which in the four eastern cercles of the region (Bandiagara, Bankass, Douentza and Koro). Due to the presence of multiple armed groups, intercommunal violence was exacerbated in those four cercles and the general security context has been highly volatile since. During the same period, Tenenkou, Mopti, Youwarou and Djenne (western cercles) recorded significantly fewer violent events; the presence of one non-state armed group deeply rooted in those cercles, implying high criminality but allowing a relatively calm situation, may partly explain a more normal rollout of agricultural activities. Cropland abandonment, as visible from space, is one of the many consequences of the widespread violence in central Mali. Damaged infrastructure and abandoned villages could also be evidenced through the exploration of Sentinel-2 composites. Figure 2 shows an example where, besides obvious cropland abandonment, settlement damage was detected: black-pixeled inhabitations are no longer visible in 2019, where there used to be built-up two years earlier. More specifically, the village at the centre of the image is Bombou, located in the cercle of Koro. According to ACLED data, this village was attacked multiple times between May and July 2018, reportedly killing tens of civilians and setting the village on fire. Another village visible on the image, located approximately 3 kilometres southwest of Bombou, seems to have also undergone cropland abandonment and settlements damage between 2017 and 2019. Black and colourful pixels (corresponding to built-up and croplands, respectively) in the 2017 3PTS (left image) are replaced in 2019 (right image) with cyan and white pixels, corresponding to natural vegetation. White tones are due to high values of NDVI throughout the period of analysis, which may be a direct consequence of the village having been set ablaze in 2018 , given that fires can have a regenerating effect on soils, a technique sometimes intentionally employed by farmers for the following season (Hodgkinson, 1998). The interpretation of the 3PTS composites, additionally validated with recent VHR imagery when it was possible (60\% of the localities), allowed for the detection of more than one hundred villages visibly destroyed or damaged between 2017 and 2019, with indications of fires that were very likely set during violent attacks, as also reported by various sources of conflict data. Testimonies gathered by Human Right Watch from villagers who had fled localities from eastern Mopti also confirms and further describes atrocities endured by communities of central Mali since 2018 (HRW, 2019).

\subsection{Operationalisation of results}

The results of the 3PTS-based cropland change analysis, as presented in this study, provided outputs befitting information needs of humanitarian actors in Mali. By offering a comprehensive map and the list of localities showing significant agricultural losses, a more precise picture of food insecurity could be drawn. This allowed for a more advanced targeting of areas in need of food assistance. As a result, these outputs were quickly absorbed into the humanitarian response planning process, notably through the Cadre Harmonisé $(\mathrm{CH})$, the biannual national food security analysis, which is led by the national early warning system in collaboration with line ministries and humanitarian actors. The goal of the $\mathrm{CH}$ is to estimate the number of food insecure people in the country and to provide coordinated targeting priorities for humanitarian response. During the $\mathrm{CH}$ sessions conducted in October 2019 and in March 2020, the results presented in this study were used as contributing factors for hard-to-reach areas in central Mali, where traditional survey data could not be collected due to insecurity. This helped inform important gaps in evaluating the 2020 lean season, which is the period between planting and harvesting, when resources from the previous agricultural season are scarce: food stocks dwindle and pasture for grazing animals is the least available. Typically, in central Mali, the lean season is from June until August. It is common for poor households to skip meals during this period, and this is the period when food insecurity is at its peak. Results contributed to the estimation of 757,217 persons considered in food insecurity for the 2020 lean season. Beyond the $\mathrm{CH}$, the unprecedented level of spatial precision provided by the results fed into humanitarian response mechanisms, as a tool to enhance geotargeting of communities impacted by the conflict. For the 2020 lean season, the World Food Programme (WFP) used cropland change results to anticipate and inform emergency response planning, by targeting their food assistance to localities impacted by cropland abandonment.

\subsection{Suitability of data pipeline}

Spatial resolution requirements for Earth Observation data were developed by the Committee on Earth Observation Satellites (CEOS) to match the observed field size for crop monitoring applications: it is specified that an appropriate spatial resolution to observe small parcel sizes $(<1.5 \mathrm{ha})$, predominant in Mali, is 10 meters maximum. According to a paper conducted by Nabil (2020), which studies the suitability of datasets to monitor cropland based on parcel size, a lower resolution such as the one of Landsat imagery (30 metres) would be insufficient to detect agricultural fields in the study area of Mopti. Besides, Sentinel2's temporal resolution of 5 days is a valuable enhancement, compared to Landsat's 16 days, as it allows for a more frequent and thus more accurate assessment of the vegetation evolution in time, also less dependent on cloudy conditions, which are 
likely in this season for central Mali, given that it corresponds to the rainy season. Finally, Sentinel-2 archive data allows to compare the current situation with two pre-conflict years, as it was launched in the course 2016 and because the security crisis hit Mopti region in 2018. For those various reasons, Sentinel-2 data is considered the most adapted for the present study and preferred over other existing optical sensors. Besides, by using openly accessible and free-of-charge data from the Copernicus mission and a platform with similar characteristics such as Google Earth Engine, the methodology presented in this study answers well the challenges faced by humanitarians and national governments in countries such as Mali : it is quick to conduct and easily reproducible with minimal resources beyond an internet connection. In 2020, based on this methodology, the WFP Regional Bureau of West and Central Africa conducted similar cropland change analyses in hard-to-reach areas across seven countries, covering an area beyond 1 million square kilometres. Concurrently, on the request of the Technical Committee of the Cadre Harmonisé, the Copernicus Emergency Management Service (CEMS), which provides on-demand detailed mapping information for selected emergency situations, also conducted cropland change analyses based on this methodology for five divisions of the Borno state (northeast Nigeria) for the 2019 agricultural season (EC-JRC, Feb 2020) and for the one of 2020 (EC-JRC, Oct 2020).

\subsection{Discussion}

While the 3PTS data offers a solution to important information gaps in hard-to-access areas, it is not without limitations and many possible ways of enhancement can be considered. The analysis results do not offer a quantitative estimate of cropland surface area changes, but propose qualitative, ready-to-use maps. Considering the lack of ground-truth samples over such areas, often extremely large and hard-to-reach, and the very heterogeneous landscapes that are characteristic of the Sahelian band, available ground-truth datasets to train machine learning models are often unsatisfactory, and classified results require exhaustive manual cleaning to achieve acceptable levels of accuracy. Yet, this accuracy is crucial for a highly sensitive topic such as agricultural changes in conflict-prone areas, especially when it is intended to be used operationally by state actors and international organizations. Supervised and unsupervised classifications were tested and performed based on 3PTS products, yet, consistent results could not be delivered in time for the utilization of the maps in the national food security analyses, leaving expert interpretation as the method of choice. However, the ease of identifying cropland through the 3PTS methodology portends its potential to be used in classifications.

Conclusions drawn from the results of the analysis are inferential. While the 3PTS method excels at identifying areas with declining cultivated surfaces, such data is rarely consumed as an impact indicator or output itself. In an operational context, it can often be used as a proxy for humanitarian conditions such as food insecurity or incidence of conflicts, as this paper contends. However, several other factors may be important drivers of changes in cultivated surfaces, notably environmental shocks (Wessels, 2007), which were not evaluated within the study. Likewise, the use of ACLED data to locate incidences of conflict may constitute another limitation, as a number of incidents are likely missing, especially in cases where the area in question is poorly covered by communication networks or where the flow of information is impeded.

\section{CONCLUSION}

This paper seeks to offer a spatial analysis toolkit adapted to the Sahelian context, based on openly accessible technologies, making this solution easily replicable, in other areas or for other years of interest. Where existing LCLU datasets and other initiatives have failed to respond to humanitarian needs in a timely and regular manner, the proposed method paves the way for an operational locality-level cropland monitoring system. By allowing for a rapid assessment of cropland abandonment at locality level, this methodology provides evidence of conflictrelated hazards in hard-to-access areas and enables to highlight specific areas at risk of food insecurity. For that, the 3PTS composite contains condensed information of the massively larger volume of underlying input scenes acquired along the agricultural season of a year of interest. The agroecological heterogeneity of the Sahelian landscape indicates that machine learning tools must be heavily localized to effectively classify cropland, in addition to a lack of appropriate training datasets (field samples), due to access restrictions. As a result, it is likely that visual interpretation will remain a more expedient method for assessing cropland changes in the context of crisis emergency response.

The analysis showed that the ongoing violence in central Mali heavily curtailed agricultural activities in the eastern part of the Mopti region: cropland abandonment, with different degrees of loss, was detected in hundreds of localities in 2019 compared to pre-conflict years. Such conclusions were corroborated with other data sources available for that year, allowing to better understand the reasons behind the significant cropland reductions, as detected with Sentinel-2 imagery. Intercommunal violence leading to attacks of villages, population displacement and the restriction of physical access to fields (villages under embargo) are the main causes for the observed changes in cropland patterns in Mopti.

\section{REFERENCES}

ACLED (Armed Conflict and Location Event Data), 2019. Project datasets. acleddata.com (19 November 2019).

Arina, O., Bicheron, P., Achard, F., Latham, J., Witt, R., Weber, J.L., 2008. The most detailed portrait of Earth. ESA Bull. 136, 25-31. doi.org/10.3390/rs9111118.

Benedetti, R., Rossini, P., 1993. On the use of NDVI profiles as a tool for agricultural statistics: The case study of wheat yield estimate and forecast in Emilia Romagna. Remote Sens. Environ., 45, 311-326. doi.org/10.1016/0034-4257(93)90113-C.

Benjaminsen, T.A., Ba, B., 2018. Why do pastoralists in Mali join jihadist groups? A political ecological explanation. $J$. $\begin{array}{lll}\text { Peasant } & \text { Stud., } & \text { 46, }\end{array}$ doi.org/10.1080/03066150.2018.1474457.

Boudinaud, L., Kamara N., Ibrahim A., 2021. Using satellite imagery in conflict-affected areas in Mali to support WFP's emergency response. Field Exchange, Issue 64. ennonline.net/fex/64/wfpsatelliteimagery (31 March 2021).

Cadre Harmonisé committee (Integrated Food Security Phase Classification), 2020. Résultats Cadre Harmonisé de Mars 2020, Fiche de Communication \& Tableau 5 - Estimation des populations. fscluster.org/mali/document/ch-resultats-cadreharmonise-mars-2020 (28 April 2020). 
CEMS (Copernicus Emergency Management Service), 2021. emergency.copernicus.eu (18 May 2021).

Centre for Humanitarian Dialogue, 2020. Redeployment of the State in Central Mali. hdcentre.org/wpcontent/uploads/2020/06/MACE_Success-stories_communityplatform_2020.web_EN.pdf (4 January 2021).

CEOS (Committee on Earth Observation Satellites). Acquisition Strategy for GEOGLAM. geoglam.org/pdf/CEOS-AcquisitionStrategy-for-GEOGLAM-Phase-1.pdf (12 March 2021).

CILSS (Permanent Interstate Committee for Drought Control in the Sahel), 2014. Cadre Harmonisé Manual Version 1.0: Identification and Analysis of Areas at Risk and Populations Affected by Food and Nutrition Insecurity in the Sahel and West Africa. reliefweb.int/report/nigeria/cadre-harmonismanual-version-10-identification-and-analysis-areas-risk-and (28 April 2020).

Defourny, P., Bontemps, S., Bellemans, N., Cara, C., Dedieu, G., Guzzonato, E., Hagolle, O., Inglada, J., Nicola, L., Rabaute, T., Savinaud, M., Udroiu, C., Valero, S., Bégué, A., Dejoux, J.F., El Harti, A., Ezzahar, J., Kussul, N., Labbassi, K., Lebourgeois, V., Miao, Z., Newby, T., Nyamugama, A., Salh, N., Shelestov, A., Simonneaux, V., Traore, P.S., Traore, S.S., Koetz, B., 2019. Near real-time agriculture monitoring at national scale at parcel resolution: Performance assessment of the Sen2-Agri automated system in various cropping systems around the world. Remote Sens. Environ., 221, 551-568. doi.org/10.1016/j.rse.2018.11.007.

Defourny, P., Kirches, G., Brockmann, C., Boettcher, M., Peters, M., Bontemps, S., Lamarche, C., Schlerf, M., Santoro, M., 2016. Land Cover CCI: Product User Guide Version 2. maps.elie.ucl.ac.be/CCI/viewer/download/ESACCI-LC-PUGv2.5.pdf (14 March 2020)

Esch, T., Üreyen, S., Zeidler, J., Metz-Marconcini, A., Hirner, A., Asamer, H., Tum, M., Böttcher, M., Kuchar, S., Svaton, V., Marconcini, M., 2018. Exploiting big earth data from space first experiences with the timescan processing chain. Big Earth Data, 2:1, 36-55. doi.org/10.1080/20964471.2018.1433790.

EC-JRC (European Commission Joint Research Center), Feb 2020. Copernicus Emergency Management Service. EMSN063: Crop change detection conflict areas, Nigeria, Final Report. emergency.copernicus.eu/mapping/list-ofcomponents/EMSN063 (10 March 2020).

EC-JRC (European Commission Joint Research Center), Oct 2020. Copernicus Emergency Management Service EMSN-083: Crop change detection in conflict areas of NE Nigeria, Final Report emergency.copernicus.eu/mapping/list-ofcomponents/EMSN083 (18 December 2020).

ESA (European Space Agency). Data products description of the Copernicus Sentinel-2 mission. sentinels.copernicus.eu/web/sentinel/missions/sentinel-2/dataproducts (5 May 2021).

ESA (European Space Agency), 2017. The Copernicus space component: Sentinels data product list. sentinel.esa.int/documents/247904/685154/Sentinel+Products+ List-Issue1-Rev1.pdf (20 March 2020).
Facebook Connectivity Lab, CIESIN Columbia University, 2016. High Resolution Settlement Layer. Source imagery (C) Digital Globe. data.humdata.org (12 January 2020).

FAO (Food and Agriculture Organisation), 2020. Land Use Domain; Update: Questionnaire on land use, irrigation, and agricultural practices. fenixservices.fao.org/faostat/static/documents/RL/RL_EN.pdf (12 December 2020).

Gingembre, L., UNICEF, OCDE, OCHA, 2019. Analyse préliminaire des risques, des vulnérabilités et des actifs de résilience dans la région du Liptako Gourma. Resilience Common Analysis and Prioritization. food-security.net/wpcontent/uploads/2019/04/Liptako-Gourma-Diagnostic27fev_FINAL.pdf (7 May 2020).

Gong, P., Wang, L., Yu, L., Zhao, Y.L., Zhao, L., Liang, L., Niu, Z., Huang, X., Fu, H., Liu, S., 2013. Finer resolution observation and monitoring of GLC: First mapping results with Landsat TM and ETM+ data. Remote Sens., 34, 2607-2654. doi.org/10.1080/01431161.2012.748992.

Gorelick, N., Hancher, M., Dixon, M., Ilyushchenko, S., Thau, D., Moore, R., 2017. Google Earth Engine: Planetary-scale geospatial analysis for everyone. Remote Sens. Environ., 202, 18-27. doi.org/10.1016/j.rse.2017.06.031.

Group on Earth Observation Global Agricultural Monitoring (GEOGLAM), 2015. Crop Assessment Tool. Ag Data Commons. geoglam.org (20 March 2020).

Hodgkinson, K. C., 1998. Sprouting success of shrubs after fire: height-dependent relationships for different strategies. Oecologia, 115, 64-72. doi.org/10.1007/s004420050492.

Human Rights Watch, 2019. How Much More Blood Must Be Spilled? Atrocities Against Civilians in Central Mali. hrw.org/report/2020/02/11/how-much-more-blood-must-bespilled/atrocities-against-civilians-central-mali (31 March 2020).

ILOSTAT (International Labour Organization), 2021. World Development Indicator for the World Bank dataset: Employment in agriculture. data.worldbank.org (16 May 2021).

Inglada, J., Arias, M., Tardy, B., Hagolle, O., Valero, S., Morin, D., Dedieu, G., Sepulcre, G., Bontemps, S., Defourny, P., Koetz, B, 2015. Assessment of an Operational System for Crop Type Map Production Using High Temporal and Spatial Resolution Satellite Optical Imagery. Remote Sens., 7, 1235612379. doi.org/10.3390/rs70912356.

IOM Displacement Tracking Matrix, 2020. République du Mali Direction Nationale du Développement Social. Rapport DTM Mars 2020 : Matrice de Suivi des déplacements. dtm.iom.int/reports/mali-\%E2\%80\%94-rapport-sur-lesmouvements-de-populations-mars-2020 (11 May 2020).

Lamarche, C., Bontemps, S., Bontemps, N., Defourny, P., Koetz, B., 2018. Validation of the ESA Sen2-Agri cropland and crop type products: lessons learnt from local to national scale experiments. Abstract for the American Geophysical Union Fall Meeting, Washington D.C., USA, 10-14 December 2018. ui.adsabs.harvard.edu/abs/2018AGUFMGC41B..07L/abstract (14 March 2021). 
Latham, J.R., Cumani, R., Rosati, I., Bloise, M., 2014. Global Land Cover SHARE (GLC-SHARE) database Beta-Release V1.0. fao.org/uploads/media/glc-share-doc.pdf (14 March 2020).

Nabil, M., Zhang, M., Bofana, J., Wu, B., Stein, A., Dong, T., Zeng, H., Shang, J., 2020. Assessing factors impacting the spatial discrepancy of remote sensing based cropland products: A case study in Africa. Int. J. Appl. Earth Obs. Geoinf., 85, 114. doi.org/10.1016/j.jag.2019.102010.

Pérez-Hoyos, A., Rembold F., Kerdiles, F., Gallego, J., 2017. Comparison of Global Land Cover Datasets for Cropland Monitoring. Remote Sens. 9, 1118. doi.org/10.3390/rs9111118.

Raleigh, C., Linke, A., Hegre, H., Karlsen, J., 2010. Introducing ACLED-Armed Conflict Location and Event Data. J. Peace Res., 47(5), 651-660. dx.doi.org/10.1177/0022343310378914.

RGA (Recensement général de l'agriculture), République du Mali., 2007. Campagne Agricole 2004-2005 : Principaux résultats définitifs, Volume I, Rapport de Synthèse. instepp.umn.edu/sites/instepp.umn.edu/files/product/downloada ble/Mali_2004-05_Vol1.pdf (17 September 2020).

Rouse, J. W., Haas, R. H., Schell, J. A., Deering, D., Deering, W., 1973. Monitoring vegetation systems in the Great Plains with ERTS, ERTS Third Symposium, NASA SP-351 I, 309317. dx.doi.org/10.13140/RG.2.1.3691.8244.

Samasse, K., Hanan, N., Tappan, G., Diallo, Y., 2018. Assessing Cropland Area in West Africa for Agricultural Yield Analysis. Remote Sens. 10, 1785. doi.org/10.3390/rs10111785.

United Nations, Department of Economic and Social Affairs, 2019. Population Division, Comprehensive Tables. World Population Prospects. population.un.org/wpp (17 April 2020).

Wei,Y., Lu M., Wu W., Ru Y, 2020. Multiple factors influence the consistency of cropland datasets in Africa. Int. J. Appl. Earth Obs. Geoinf., 89. doi.org/10.1016/j.jag.2020.102087.

Wessels, K.J., Prince, S.D., Malherbe, J., Small, J., Frost, P.E., VanZyl, D., 2007. Can human-induced land degradation be distinguished from the effects of rainfall variability? A case study in South Africa. J. Arid Environ., 68, 271-297. doi.org/10.1016/j.jaridenv.2006.05.015.

White, J.C., Wulder, M.A., Hobart, G.W., Luther, J.E., Hermosilla, T., Griffiths, P., Coops, N.C., Hall, R.J., Hostert, P., Dyk, A., Guindon. L., 2014. Pixel-Based Image Compositing for Large-Area Dense Time Series Applications and Science. Can. J. Remote. Sens., 40(3), 192-212. doi.org/10.1080/07038992.2014.945827.

\section{APPENDIX}

Boudinaud, L., 2019. Google Earth Engine script for 3PTS composites for cropland change interpretation. code.earthengine.google.com/c1c5529b8f9b997a8ec2afe12d3dc $95 \mathrm{~d}$. 